\title{
A Rare Cause of Methemoglobinemia: How Safe are So-called Biopesticide?
}

\author{
Poonam Gupta ${ }^{1}$, Pradeep K Verma ${ }^{2}$
}

\begin{abstract}
With increasing awareness of "greener" environment, market is flooded with biopesticide. Natural insecticides can be chemical, mineral, or biological. We report an unusual case of methemoglobinemia after deliberate ingestion of an insecticide containing extract of pine oil and azadirachtin oil, Ti oil, and kerosene. On literature search, no such case report has been documented so far.

Keywords: Biological extract, Insecticide, Methemoglobinemia.

Indian Journal of Critical Care Medicine (2020): 10.5005/jp-journals-10071-23373
\end{abstract}

\section{INTRODUCTION}

Methemoglobinemia occurs when hemoglobin is oxidized to form methemoglobin (MetHb), rendering it incapable of oxygen transport, and if severe, it leads to tissue hypoxia. ${ }^{1}$ Most commonly, induced methemoglobinemia can arise after exposure to a variety of compounds and exogenous oxidizing agent. ${ }^{2}$ We report herein a case of acquired methemoglobinemia caused after intentional ingestion of biopesticide. This case report highlights the importance of considering the possibility of methemoglobinemia in cases of exposure to pesticide with biological compounds presenting with cyanosis, dark blood, and saturation gap. Early recognition and management can result a favorable outcome.

\section{Case Description}

A 32-year-old lady was brought to emergency department (ED) with alleged self-consumption of an insecticide. In ED, her Glasgow Coma Scale (GCS) was $13 / 15$, and vitals were stable with a heart rate of $160 /$ minute and a blood pressure of $110 / 70 \mathrm{~mm} \mathrm{Hg}$. She was referred to our intensive care unit for observation. On arrival in the ICU (six hours after ingestion of pesticide), she was drowsy with GCS of 10/15, agitated and cyanosed (dark brown blue), her oxygen saturation of blood $\left(\mathrm{SpO}_{2}\right)$ was $86 \%$ on $\mathrm{FiO}_{2} 0.6 \%$. She had no history of premorbid illnesses. Patient was intubated and put on mechanical ventilation (assist control mode). Organophosphorus poisoning was suspected and infusions of injections atropine 1 $\mathrm{mg} /$ hour and PAM-500 mg/hour were started. An arterial blood gas analysis revealed a $\mathrm{PaO}_{2}$ of $347 \mathrm{~mm} \mathrm{Hg}$ on a $\mathrm{FiO}_{2}$ of 1 , and the $\mathrm{SpO}_{2}$ was only $86 \%$. Patient's blood was noticed to be muddy brown in color. Saturation gap measured by pulse oximetry was $86 \%$ on $100 \%$ oxygen and in $\mathrm{ABG} \mathrm{PaO}_{2}$ was $347 \mathrm{~mm} \mathrm{Hg}$, and dark brown blood led to a high suspicion of methemoglobinemia secondary to ingestion of insecticide.

Pralidoxamine [2-pyridine aldoxime methyl chloride (PAM)] and atropine were stopped. Her relative were also able to retrieve the empty bottle $(100 \mathrm{~mL}$ ) of pesticide called "NIMOLIN" (composition: azadirachtin oil 40\%, Ti oil 15\%, pine oil 20\%, and kerosene oil; Figs 1 and 2).

Blood sample was sent for estimation of methemoglobin levels. Her initial methemoglobin level was found to be $30 \%$. Patient was managed conservatively, with mechanical ventilation, fentanyl infusion, and tablet vitamin C $500 \mathrm{mg}$ BID. The patient started showing signs of improvement, and her $\mathrm{SpO}_{2}$ gradually improved \begin{tabular}{l}
\hline 1,2Department of Anesthesia and Intensive Care, Safdarjang Hospital \\
and Vardhman Mahavir Medical College, New Delhi, India \\
Corresponding Author: Poonam Gupta, Department of Anesthesia \\
and Intensive Care, Safdarjang Hospital and Vardhman Mahavir \\
Medical College, New Delhi, India, Phone: +91-011-9818623450, \\
e-mail: p.gupta182@gmail.com
\end{tabular}

How to cite this article: Gupta P, Verma PK. A Rare Cause of Methemoglobinemia: How Safe are So-called Biopesticide? Indian J Crit Care Med 2020;24(3):208-209.

Source of support: Nil

Conflict of interest: None

to $92-95 \%$ on day 2. Her sensorium improved further, the $\mathrm{SpO}_{2}$ increased to $95 \%$ on day 3 , and to $95-97 \%$ on day 4 , and she was successfully weaned off the ventilator after 4 days. The patient was subsequently extubated on day 4 and continued to maintain a $\mathrm{SpO}_{2}$ of $98 \%$ on face mask with $5 \mathrm{~L} /$ minute of oxygen. MetHb levels slowly decreased and reached levels of $<2 \%$ on the day of discharge (day 6 ).

\section{Discussion}

Methemoglobinemia occurs when MetHb levels exceeds $2 \%$. Normal MetHb levels are $<1 \%$. Symptoms of methemoglobinemia correlate with MetHb level in healthy patients. Cyanosis is reported

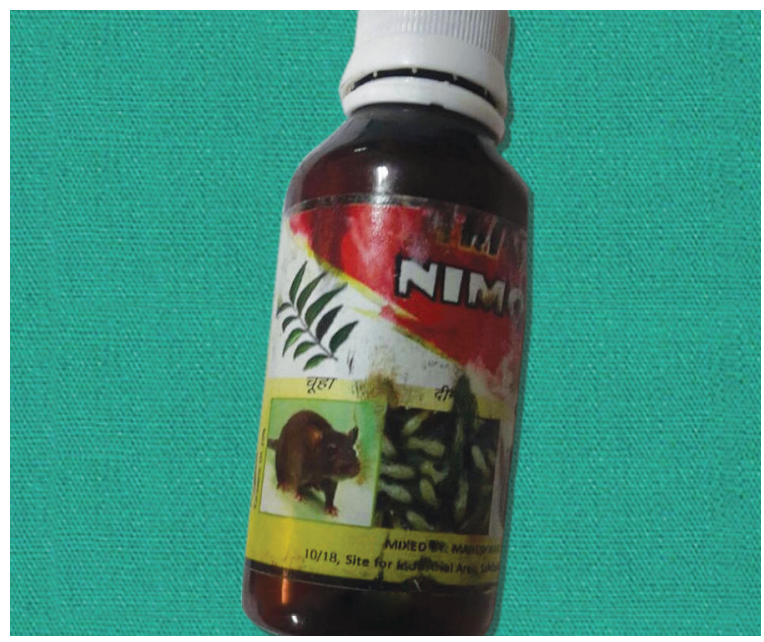

Fig. 1: Bottle of insecticide

C) The Author(s). 2020 Open Access This article is distributed under the terms of the Creative Commons Attribution 4.0 International License (https://creativecommons. org/licenses/by-nc/4.0/), which permits unrestricted use, distribution, and non-commercial reproduction in any medium, provided you give appropriate credit to the original author(s) and the source, provide a link to the Creative Commons license, and indicate if changes were made. The Creative Commons Public Domain Dedication waiver (http://creativecommons.org/publicdomain/zero/1.0/) applies to the data made available in this article, unless otherwise stated. 


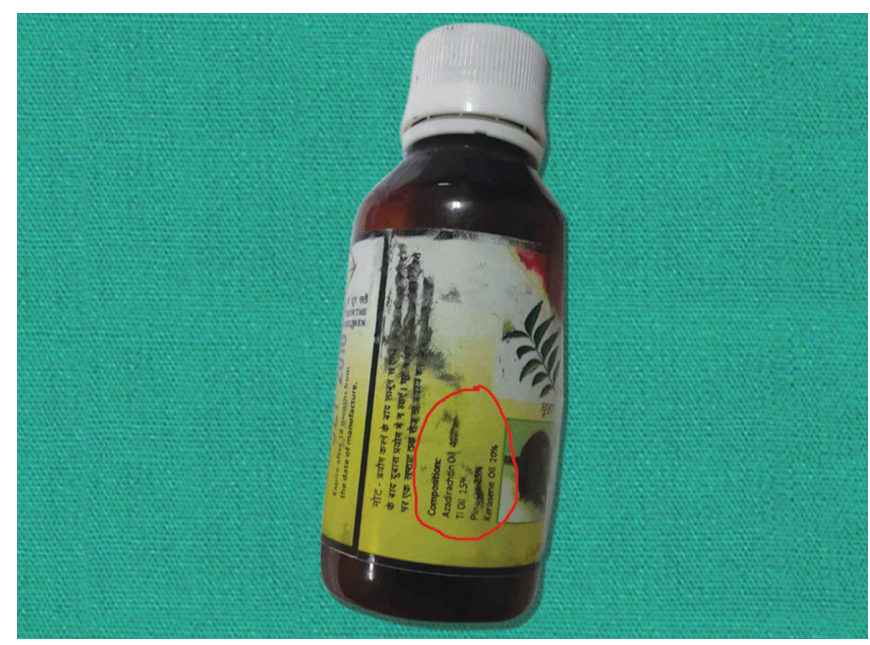

Fig. 2: Composition of insecticide

at a MetHb level $>15 \%$ in nonanemic patients; anxiety, headache, and dizziness at a MetHb level $>20 \%$; fatigue, confusion, and tachypnea between $30 \%$ and 50\%; and arrhythmias, acidosis, seizures, and even death at a MetHb level $>50 \%{ }^{2}$

Diagnostic suspicion of methemoglobinemia should be considered on clinical findings: cyanosis out of proportion to respiratory status and normal $\mathrm{PaO}_{2}$, which does not improve with administration of $\mathrm{O}_{2}$, "oxygen saturation gap," and chocolate brown, blue, or black on blood sampling.

The first-line treatment of methemoglobinemia is intravenous administration of methylene.

It is recommended specifically when MetHb levels are more $>30 \%$ or symptoms were severe. ${ }^{3}$ Alternative treatments, such as ascorbic acid or $\mathrm{N}$-acetylcysteine, can also be used if methylene blue is unavailable or contraindicated. Exchange blood transfusion is recommended when methylene blue or alternative treatments are ineffective. .,5 $^{4}$

The insecticide our patient had consumed reportedly contains biological extracts (extract of pine oil and azadirachtin oil), Ti oil, and kerosene. It was marketed with no reports of toxicity and no mention of an antidote. A literature survey revealed azadirachtin oil to be a metabolite of neem seed, Ti oil is from tea tree oil, and pine oil is extracted from pine foliage, but no case reports or review article evidencing of such complication was found. However, search has shown that biological extracts are known to be rich in nitrogenous products and may potentially cause methemoglobinemia. ${ }^{6}$

In our patient, diagnosis of methemoglobinemia was made on triad of saturation gap, cyanosis, and dark blood. Early recognition and on symptomatic treatment led to recovery with normal neurological function.

In conclusion, as more and more natural and herbal products are being marketed, treating clinician should be cautious of the numerous compounds without details of the composition which can cause methemoglobinemia. Methemoglobinemia must be considered in the differential diagnosis in unknown poisoning with unexplained cyanosis, with low oxygen saturation on pulse oximetry, normal $\mathrm{PaO}_{2}$, and the presence of chocolate-colored blood.

\section{References}

1. Mansouri A, Lurie AA. Concise review: methemoglobinemia. Am J Hematol 1993;42(1):7-12. DOI: 10.1002/ajh.2830420104.

2. Skold A, Cosco DL, Klein R. Methemoglobinemia: pathogenesis, diagnosis, and management. South Med J 2011;104(11):757-761. DOI: 10.1097/SMJ.0b013e318232139f.

3. Yang JJ, Lin N, Lv R, Sun J, Zhao F, Zhang J, et al. Methemoglobinemia misdiagnosed as ruptured ectopic pregnancy. Acta Anaesthesiol Scand 2005;;49(4):586-588. DOI: 10.1111/j.1399-6576.2005.00640.x.

4. Nascimento TS, Pereira ROL, Mello HLD, Costa J. Methemoglobinemia: from diagnosis to treatment. Rev Bras Anestesiol 2008;58(6):651-664. DOI: 10.1590/s0034-70942008000600011.

5. Bhat $\mathrm{P}$, Sisler I, Collier AB. Exchange transfusion as treatment for rasburicase induced methemoglobinemia in a glucose-6phosphate dehydrogenase deficient patient. Pediatr Blood Cancer 2008;51(4):568. DOI: 10.1002/pbc.21582.

6. George T, Shaikh A, Thomas L, Kundavaram AP. Severe methemoglobinemia due to insecticide poisoning. Indian J Crit Care Med 2014;18(2):113-114. DOI: 10.4103/0972-5229.126087. 